\title{
DENTAL PRACTITIONERS' ATTITUDES, SUBJECTIVE NORMS AND INTENTIONS TO PRACTICE ATRAUMATIC RESTORATIVE TREATMENT (ART) IN TANZANIA
}

\author{
Emil N. KIKWILU ${ }^{1}$, Jo E. FRENCKEN ${ }^{2}$, Jan MULDER ${ }^{3}$, Joyce R. MASALU ${ }^{4}$
}

\author{
1- DDS, MDent, Department of Preventive and Community Dentistry, Dental School, Muhimbili University of Health and Allied Sciences, Dar es \\ Salaam, Tanzania. \\ 2- DDS, MSc, PhD, Nijmegen International Centre for Oral Health, Radboud University Nijmegen Medical Centre, College of Dental Sciences, \\ Nijmegen, the Netherlands. \\ 3- MSc, Department of Preventive and Restorative Dentistry, Radboud University Nijmegen Medical Centre, College of Dental Sciences, Nijmegen, the \\ Netherlands. \\ 4- DDS, MPH, PhD, Department of Preventive and Community Dentistry, Dental School, Muhimbili University of Health and Allied Sciences, Dar es \\ Salaam, Tanzania.
}

Corresponding address: J. E. Frencken - Nijmegen International Centre for Oral Health - Radboud University Nijmegen Medical Centre - College of Dental Sciences - P.O. Box 9101 - 6500 HB - Nijmegen, the Netherlands - e-mail: j.frencken@dent.umcn.nl

Received: April 25, 2008 - Modification: June 1, 2008 - Accepted: June 6, 2008

\begin{abstract}
$T_{\text {he }}$

he aim of this study was to describe the attitude and subjective norm of dental practitioners towards practicing the atraumatic restorative treatment (ART) in Tanzania. A pre-tested questionnaire on attitudes and subjective norms to practice ART was mailed to all 147 dental practitioners working in the regional and district government clinics. The independent variables were: gender, working experience, qualification and ever heard of ART. The dependent variables were: attitude, subjective norm and intention to practice ART. Chi-square tests and multiple regression analysis were used to test for effects between independent and dependent variables. Significance level was set at 5\%. A total of 138 practitioners returned completed questionnaires. More experienced dental practitioners encountered moderate social pressure than less experienced dental practitioners, who met strong social pressure ( $\mathrm{p}=0.045)$. A total of $73.2 \%$ of dental practitioners felt that ART was worth introducing in Tanzania, $92.8 \%$ recommended ART training for all dental practitioners and $97.8 \%$ recommended inclusion of ART in dental curricula. Positive attitude, strong subjective norm and high intention to practice ART were recorded in $76.3 \%, 28.1 \%$ and $90.6 \%$ of the practitioners, respectively. Only subjective norm had a statistically significant influence on the intention to practice ART $(\mathrm{p}<0.0001)$. The results indicated that dental practitioners were willing to have ART introduced in Tanzania and had positive attitudes towards practicing this technique. Nevertheless, their intention to perform ART was strongly influenced by social pressures. Therefore, in order to have a successful introduction of ART in Tanzania, people who matter in the daily practice of dental practitioners need to accept and appraise the ART approach positively.
\end{abstract}

Key words: Atraumatic Restorative Treatment. Oral health, attitude. Dental practitioner. Tanzania.

\section{INTRODUCTION}

In 1994, the Ministry of Health of Tanzania expressed its dissatisfaction regarding the insignificant contribution of restorative care to the oral health of Tanzanians ${ }^{23}$. In response, regional dental officers blamed the non-functioning dental equipment in their clinics as the main reason for the low rates of restorative care offered to Tanzanians ${ }^{23}$. In 1996, the Ministry of Health reacted by introducing the Atraumatic Restorative Treatment (ART) approach to dental practitioners in the regions, through a one-day seminar. As the ART approach relies on the use of hand instruments only ${ }^{9}$, the Ministry of Health considered that this measure would obviate the need to replace or repair rotary dental equipment ${ }^{24}$. It was hoped that the regional dental officers would acquire the skills and practice ART in their clinics ${ }^{24}$.

Epidemiological data and summary data from clinics, for the years following the seminars, did not show an increase in restorative care in Tanzania ${ }^{14,19,21}$. In 2002, the Ministry of Health stressed the importance of ART in managing dental caries in outreach clinics, and regional and district hospitals, by including this caries management approach in the policy guidelines for oral healthcare in Tanzania ${ }^{22}$. However, it was recently concluded that the efforts to increase restorative care through the introduction of ART had not made a significant impact on oral healthcare delivery in Tanzania ${ }^{14}$. Dental extractions still constituted over $90 \%$ of all forms of dental treatment, whereas restorative care accounted for less 
than $5 \%{ }^{14}$.

Studies have indicated the importance of attitudes and subjective norms in peoples' intentions ${ }^{12,15}$, with regard to the actual performance of a given health behavior ${ }^{3,4,6,10}$, including implementation of an innovation in healthcare ${ }^{5,8,16}$, and initiating a specific type of treatment ${ }^{7,13}$. These studies indicate that a positive attitude and/or subjective norm towards performing a certain behavior contribute to the intentions to practice that behavior. Intentions have been shown as proxy measures of actual behavior and high intenders have been found more likely to perform a given behavior than non-intenders. Nevertheless, Ajzen and Fishbein $^{1}$ (1980) stressed that for the attitude and subjective norm to predict a given action, the action must be voluntary in nature. It was not known whether authority for decisions regarding practicing ART in a government dental clinic rested with dental practitioners and whether or not they could decide to undertake the ART approach.

It was felt that a study covering the attitude and subjective norms of dental practitioners towards practicing ART in Tanzania might reveal some psychosocial barriers that could have hindered dental practitioners from practicing ART in the past. Results might enable the authorities to find ways of addressing these barriers with the intention of facilitating the practice of ART in Tanzania. The aim of this study was therefore to describe the attitudes and subjective norms of dental practitioners towards practicing ART in Tanzania.

\section{MATERIAL AND METHODS}

Written approval for this study was obtained from the Research Ethics Committee of the Muhimbili University College of Health Sciences by a letter with reference MU/ RP/AEC/VOL. II/130.

\section{Development of the Questionnaire}

The authors could not find a questionnaire on attitudes and intentions of dental practitioners towards practicing ART. Therefore, a questionnaire had to be developed. Its construction followed the step-by-step guidelines for constructing questionnaires based on the Theory of Planned Behavior $^{11}$. Since some dental practitioners had never practiced ART, 34 of them were asked to read a passage that described a step-by-step procedure for placing ART restorations and ART sealants ${ }^{9}$. Research findings on survival rates of ART restorations and ART sealants, as well as on pain experienced by patients during ART restorative procedures were also presented, in order to enable respondents to form their own opinions about ART. Practitioners were then asked to list positive and negative aspects of practicing ART in a dental clinic. A list of 10 was extracted from the answers. The proxy adjectives were then assigned to the 10 qualities extracted from the responses given by the dental practitioners. Using these adjectives, a questionnaire with a 7 -interval bipolar scale $(-3=$ extremely bad to $+3=$ extremely good) was constructed to allow respondents to rate their assessment of practicing ART in their clinics. The questionnaire was then administered to the same 34 dental practitioners. The responses were analyzed for correlation and internal consistency. Seven adjectives had significant inter-item correlations at $\mathrm{p}<0.05$ and were used to construct the final questionnaire on direct attitude.

Subjective norms, which are the individual's perceptions of the social pressure from important others to engage or abstain from a given behavior ${ }^{2}$ (in the current study, practicing ART in ones clinics) were also measured. In order to measure subjective norms, 2 descriptive items (items that aim at reflecting whether important others also perform the behavior in question) and 5 items with injunctive qualities (items that allow a respondent to indicate whether important others approve or disapprove the behavior $)^{2}$ were constructed and administered to the same 34 dental practitioners. Inter-item Spearman's correlation coefficients were calculated. Four items with injunctive qualities and one descriptive item met the criteria of having a significant correlation at $\mathrm{p}<0.05$, and were included in the final questionnaire. Three items with a statistically significant inter-item correlation coefficient $(p<0.05)$ were used to measure the intention to practice ART.

The final questionnaire applied to the practitioners consisted of three sections: a) personal details; b) overall opinion on adopting ART in Tanzania; c) attitude, subjective norms and intention to practice ART in their clinics if they received training in ART (Table 1).

\section{Selection of the Study Population}

The target population comprised all dental practitioners working in health centers and in regional and district government hospitals in mainland Tanzania. In 2003, 147 dental practitioners were working in these institutions: 22 dental officers (DO), 70 assistant dental officers (ADO) and 55 dental therapists (DT). Since the total number of dental practitioners was small, no sampling was done.

\section{Procedure for Obtaining the Names and Addresses of the Dental Practitioners}

Addresses of dental practitioners working in government health facilities were obtained from the office of the Chief Dental Officer in the Ministry of Health. As this list had last been updated in 2001, confirmation regarding the names, numbers and working stations of dental practitioners in each region was necessary. Regional dental officers were called and e-mail or short mobile phone messages were used to supply updated information about names, working stations and qualifications.

The pre-tested questionnaire, introductory letter and a stamped envelope for returning the filled questionnaire were mailed individually to all dental practitioners in mainland Tanzania. After 2 months and, finally after 4 months, a reminder letter, the questionnaire and a stamped envelope were sent to all those who had not yet returned the questionnaire. 
TABLE 1- Questionnaire on opinion of dental practitioners regarding the introduction and adoption of ART in daily clinical practice in Tanzania

a) Personal particulars

1. Region .......... 2. Hospital/Clinic Name

4. Your sex is (1) Male; (2) Female

6. Experience in years as a dental practitioner. [.... years

7. Professional qualification. (1) DDS/BDS/MD Stomatol; (2) ADO; (3) Dental Therapist

b) Overall opinion on adopting ART in Tanzania

8. Is ART a technique that is worth adopting in Tanzania for restoring teeth in dental clinics? (1) Yes; (2) No; (3) Not sure

9. Would you recommend that ART be taught to all dental practitioners in Tanzania? (1) Yes; (2) No; (3) Not sure

10. Would you be pleased if Central Oral Health Unit (COHU) recommended that ART be part and parcel of oral health care in Tanzania?

(1) Yes; (2) No; (3) Not sure

11. Would you recommend that ART be incorporated in the curricula of all dental schools in Tanzania, (DDS, ADO and Dental Therapist)?

(1) Yes; (2) No; (3) Not sure

c) Attitude, subjective norm and intention to practice ART in their clinics

12. I believe that making at least two (2) ART filings each working day in my clinic as from next financial year is

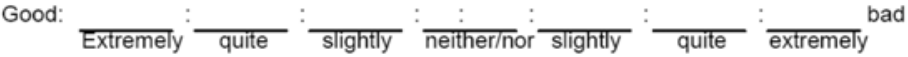

Foolish: Extremely $\frac{}{\text { quite }}: \frac{}{\text { sightly }} \frac{\vdots}{\text { neithernor }} \frac{}{\text { sightly }}: \frac{}{\text { quite }}$ wise

Ethical: $\quad$ Extremely $\frac{}{\text { quite }} \frac{:}{\text { slightly }} \frac{\text { neither/nor }}{\text { slightly }}: \frac{\text { unethical }}{\text { quite }}$

Harmful: Extremely $\frac{}{\text { quite }} \frac{}{\text { slightly }} \frac{\vdots}{\text { neither/nor }} \frac{\text { beneficial }}{\text { slightly }}$

Nice:

$\begin{aligned} & \begin{array}{l}\text { Degrading } \\ \text { dentistry: }\end{array} \text { Extremely } \\ & \text { quite }\end{aligned} \frac{\vdots}{\text { slightly }} \frac{:}{\text { neither/nor }} \frac{}{\text { sightly }}=\frac{\text { advanced }}{\text { quite }}$

Credible:

13. If people who are important to me were given explanations on what ART is, most of them would think that I should make at least two (2) ART fillings each working day in my clinic as from next financial year.

Likely: $\overline{\text { Extremely }} \frac{}{\text { quite }} \frac{}{\text { slightly }} \frac{}{\text { neither/nor }} \overline{\text { slightly }} \frac{}{\text { quite }} \frac{}{\text { extremely }}$ unlikely

14. If people in my life whose opinion I value were given explanations on what ART is, they would approve my making at least two (2) ART fillings each working day in my clinic as from next financial year.

Likely: $\overline{\text { Extremely }} \frac{}{\text { quite }} \frac{}{\text { slightly }} \frac{}{\text { neither/nor }} \overline{\text { slightly }} \frac{}{\text { quite }} \frac{}{\text { extremely }}$ unlikely

15. Given the explanations on what ART is, it is expected of me that I make at least two (2) ART fillings each working day in my clinic as from next financial year.

Likely: $\overline{\text { Extremely }} \frac{}{\text { quite }} \frac{}{\text { slightly }} \frac{}{\text { neither/nor }} \overline{\text { slightly }} \frac{}{\text { quite }} \cdot \frac{}{\text { extremely }}$ unlikely

16. If the dental practitioners who are important to me were given explanations on what ART is, they would make at least two (2) ART fillings each working day in their clinics as from next financial year.

Likely: $\frac{}{\text { Extremely }} \frac{}{\text { quite }}: \frac{}{\text { slightly }} \cdot \frac{}{\text { neither/nor }} \frac{}{\text { slightly }} \cdot \frac{}{\text { quite }} \cdot$ unlikely

17. If the dental practitioners whose opinions I value were given explanations on what ART is, they would make at east two (2) ART fillings each working day in their clinics as from next financial year.

Likely: $\overline{\text { Extremely }} \frac{}{\text { quite }} \overline{\text { slightly }} \frac{}{\text { neither/nor }} \overline{\text { slightly }} \frac{}{\text { quite }} \frac{}{\text { extremely }}$ unlikely

18. Given the explanations on what ART is, my medical colleagues would think that I should make at least two (2) ART fillings each working day in my clinic as from next financial year

Likely: $\overline{\text { Extremely }} \frac{}{\text { quite }} \frac{}{\text { slightly }} \frac{}{\text { neither/nor }} \overline{\text { slightly }} \frac{}{\text { quite }} \frac{}{\text { extremely unlikely }}$

19. Given the training on ART, I intend to make at least two (2) ART fillings each working day in my clinic as from next financial year.

Likely: $\overline{\text { Extremely }} \frac{}{\text { quite }} \frac{}{\text { slightly }}: \overline{\text { neither/nor }} \frac{}{\text { slightly }}: \frac{}{\text { quite }} \cdot \frac{}{\text { extremely }}$ unlikely

20. Given the training on ART, I will try to make at least two (2) ART fillings each working day in my clinic as from next financial year.
true:

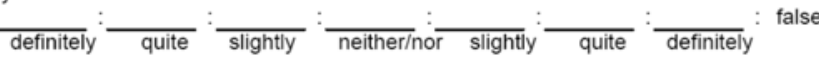

21. Given the training on ART, I plan to make at least two (2) ART fillings each working day in my clinic as from next financial year.

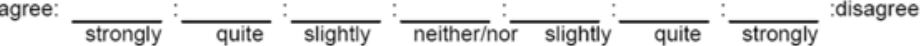




\section{Statistical Analysis}

\section{Data Entry and Processing}

All data were entered into a computer, using SPSS software, version 11.5 (SPSS Inc. Chicago IL, USA, 2002). After being checked for accuracy, the data were transferred to SAS software (SAS Institute, Cary, NC, USA), for statistical analysis by the statistician (JM) of the College of Dental Sciences of the Radboud University Nijmegen, in the Netherlands.

\section{Reliability}

The test-retest of the items resulted in a correlation coefficient of 0.98 . For the items constituting attitude, subjective norm and intention, Cronbach's alpha was calculated to ascertain their internal consistency. The alpha values were $0.80-0.81$, as summarized in Table 2 .

\section{Variables construction for statistical analysis}

The independent variables used in the analysis were: gender (male/female); working experience ( $<11$ years/11+ years); qualification (degree/advanced diploma/ordinary diploma); and ever heard of ART (yes/no). The overall opinion about adoption of ART in Tanzania was assessed by four direct questions on the suitability of ART in Tanzania, with options: $y e s=1$, no $=2$, not $\operatorname{sure}=3$. These were dichotomized by combining "no" and "not sure" into "no" and retaining the "yes" option. Scores for the 7 items used to measure attitude were summed up to form a total attitude score. Scores for 5 items used to measure subjective norm were combined to form a total subjective norm score. Scores for 3 items used to measure intention formed a total intention score. The total score for each construct was divided by the number of items used to compute it. The resulting scores ranged from -3 to +3 . Using the following cut-off points: 3.0 to $-1.5 ;-1.49$ to 1.49 ; and 1.5 to 3.0 , adopted from Roth, et al. ${ }^{18}$ (2003), these scores were classified into three categories, each representing the level of a given construct. The dependent variables were: attitude (negative, neutral and positive); subjective norm (weak, moderate and strong social pressure) and intention (low, moderate and strong intention). Frequency distributions of the categories of each construct were generated and differences in constructs between different levels of independent variables were tested by Chi-square tests at $5 \%$ significance level. The total scores for the 3 constructs were used in a multiple regression analysis to determine the relative contribution of attitude and subjective norm to the intention to practice ART.

\section{RESULTS}

Of the total of 147 dental practitioners working in the government clinics in regions and districts, 138 responded to the questionnaires, which resulted in a response rate of $96 \%$. Female respondents were 34 and most of the practitioners were either assistant dental officers $(n=64)$ or dental therapists $(n=54)$. Twenty respondents were dental officers. Only working experience had an influence on the

TABLE 2- Items used to measure attitude, subjective norm and intention to practice ART and their reliability coefficient (Cronbach's $\alpha$ )

Construct measured

Attitude

Practicing ART in my clinic is

- good/bad

- wise/foolish

- ethical/unethical

- beneficial/harmful

- nice/awful

- advancing/degrading dentistry

- credible/shameful

- Important people think that I should make ART restorations

People I value think that I should make ART restorations

- I am expected to make ART restorations

Practitioners who are important to me would make ART restorations

Practitioners who I value would make ART restorations

- I intend to make ART restorations in my clinic

- I will try to make ART restorations in my clinic

- I plan to make ART restorations in my clinic 
TABLE 3- Percent distribution of positive responses given by 138 Tanzanian dental practitioners to 4 questions regarding the introduction of ART in Tanzania

\begin{tabular}{ll}
\hline Question & Yes \\
\hline Is ART worth practicing in Tanzania? & 73.2 \\
Would you recommend ART training to all practitioners? & 92.8 \\
Should COHU* recommend wide use of ART in Tanzania? & 95.7 \\
Would you recommend ART to be included in the dental curriculum? & 97.8 \\
\hline
\end{tabular}

${ }^{*} \mathrm{COHU}=$ Central Oral Health Unit in the Ministry of Health

TABLE 4- Percent distribution of responses to attitude, subjective norm and intention to practice ART given by 138 Tanzanian dental practitioners

\begin{tabular}{lr}
\hline Behavioral construction & $\%$ \\
\hline Attitude & \\
· Positive attitude & 76.3 \\
· Neutral attitude & 23.7 \\
· Negative attitude & 0.0 \\
Subjective norm & \\
· Strong social pressure & 28.1 \\
· Moderate social pressure & 74.9 \\
· Weak social pressure & 0.0 \\
Intention & \\
· Strong intention & 90.6 \\
- Moderate intention & 9.4 \\
· Low/no intention & 0.0 \\
\hline
\end{tabular}

subjective norm of the dental practitioners. Significantly more experienced dental practitioners encountered moderate social pressure, compared to less-experienced dental practitioners, who reported strong social pressure $(\mathrm{p}=$ $0.045)$.

Table 3 summarizes the responses to the 4 questions about introducing ART in Tanzania. Seventy-three percent of dental practitioners felt that ART was worth introducing in Tanzania. More than $90 \%$ recommended that all dental practitioners in government service be trained in ART for its wide use in Tanzania and that all dental curricula should include ART.

The percent distribution of 138 practitioners according to degree of attitude, subjective norm and intention to practice ART is presented in Table 4. All dental practitioners had a moderate to strong positive attitude towards practicing ART. The proportion of practitioners who had a positive attitude, strong subjective norm and high intention to practice ART rated $76.3 \%, 28.1 \%$ and $90.6 \%$, respectively. Only subjective norm had a statistically significant influence on the intention to practice ART $(\mathrm{p}<0.0001)$.

\section{DISCUSSION}

The data were collected from $96 \%$ of all dental practitioners working in government dental clinics. The interitem correlations and Cronbach's alpha were high, indicating high internal consistence and reliability. Therefore the findings of the analysis were considered reliable.

The high percentage $(92.8 \%)$ of dental practitioners who recommended wide use of ART in Tanzania, having all dental practitioners trained in ART and inclusion of ART into dental school curricula indicates that practitioners had no objection to country-wide introduction of ART in Tanzania. Nevertheless, a quarter of these practitioners were of the opinion that ART was not worth practicing in Tanzania. This may be the result of a common fear of change. Fear of change has been shown to be one of the obstacles to a broad uptake of clinical guidelines in Australia ${ }^{20}$. In some situations it is described as professional uncertainty and disempowerment ${ }^{11}$ or as part of a clinical inertia paradigm ${ }^{17}$. It is reasonable to assume that dental practitioners may fear that they might not achieve the same success as they do when using traditional modes of treating dental caries. They may also fear possible disapproval of the innovation from patients, caused by perceptions that treating dental caries by ART procedures may be inferior to using rotary instruments.

Unlike the findings of Freeman and Adams ${ }^{8}$ (1991) that dentists with stronger attitudes had higher intentions towards treatment of special needs patients than those with weaker attitudes, the present study showed that attitude did not contribute significantly to the intention to practice ART. Subjective norm, on the other hand, had a significant influence on intentions to practice ART. This suggests that dental practitioners in Tanzania respond more positively to social pressures with regard to treatment choice. The indication is that practitioners will use ART if the people important to them (council director, colleagues and patients) approve of ART. This may indicate that practicing ART in government dental clinics in Tanzania is not a purely volitional behavior. An employee will do whatever the employer directs. On the other hand, it may reflect the mindset of many Tanzanian workers, who tend to be passive in bringing innovations to their workplaces because the institutions belong to the government, and employees have nothing to lose or gain in relation to the success or failure of these institutions ${ }^{25}$. The implication is that for countrywide 
introduction of ART, oral health authorities need not to bother too much about the attitude of practitioners towards ART. Instead, they should ensure that decision-makers in the districts and councils support the introduction and adoption of this form of therapy.

\section{CONCLUSIONS}

The study indicated that dental practitioners were willing to have ART introduced in Tanzania and that they had a positive attitude towards practicing this treatment approach. Nevertheless, their intention to practice ART was strongly influenced by social pressures. Therefore, in order to have a successful introduction of ART in Tanzania, people who matter in the daily practice of dental practitioners need to accept and appraise the ART approach positively.

\section{ACKNOWLEDGEMENTS}

The authors wish to thank the dental practitioners for their time spent in responding to the questionnaire.

\section{REFERENCES}

1- Ajzen I, Fishbein M. Understanding attitude and predicting social behaviour. Englewood-Cliffs NJ: Prentice-Hall; 1980.

2- Ajzen I. Construction of a standard questionnaire for the Theory of Planned Behaviour [text on the internet]. Amherst: University of Massachusetts; 2002 [cited 2008 Apr 24]. Available from: http:// people.umass.edu/aizen/pdf/tpb.measurement.pdf.

3- Ajzen I. Nature and operation of attitude. Annu Rev Psychol. 2001;52:27-58

4- Armitage CJ, Conner M. Efficacy of the theory of planned behaviour: a meta-analytic review. Br J Soc Psychol. 2001;40:471-99.

5- Bernaix LW. Nurses' attitude, subjective norm and behavioural intentions toward support of breastfeeding mothers. J Hum Lact. 2000;16:201-9.

6- Bonetti D, Pitts NB, Eccles M, Grimshaw J, Johnston M, Steen N, et al. Applying psychological theory to evidence-based clinical practice: identifying factors predictive of taking intra-oral radiographs. Soc Sci Med. 2006;63:1889-99.

7- Brennan DS, Spencer AJ. The role of dentist, practice and patient factors in the provision of dental services. Community Dent Oral Epidemiol. 2005;33:181-95.

8- Freeman R, Adams E. The prediction of dentists'work behaviour; factors affecting choice or intention in the treatment of special need patients. Community Dent Health. 1991;8:213-9.

9- Frencken JE, Pilot T, Sangpaisan Y, Phantumvanit P. Atraumatic Restorative Treatment (ART): rationale, technique, and development. J Public Health Dent. 1996;56:135-40.

10- Godin G, Kok G. The theory of planned behavior: a review of its applications to health-related behaviors. Am J Health Promot. 1996;11:8798 .
11- Kai J, Beavan J, Faull C, Dodson L, Gill P, Beighton A. Professional uncertaininty and disempowerment responding to ethinic diversity in health care: a qualitative study. PloS Med. 2007;4:1766-75.

12- Kim CJ, Yoo HR, Yoo MS, Kwon BE, Hwang KJ. Attitude, beliefs, and intentions to care for SARS patients among Korean clinical nurses: an application of theory of planned behaviour. Taehan Kanho Hakhoe Chi. 2006;36:596-603.

13- Klock KS. Patients' perceptions of the decision-making process leading to extraction of permanent teeth in Norway. Community Dent Oral Epidemiol. 1995;23:165-9.

14- Mandari GJ, Matee MI. Atraumatic Restorative Treatment (ART): the Tanzanian experience. Int Dent J. 2006;56:71-6.

15- Michie S, Lester K. Words matter: increasing the implementation of clinical guidelines. Qual Saf Health Care. 2005;14:367-70.

16- Millstein SG. Utility of the theories of reasoned action and planned behaviour for predicting physician behaviour: a prospective analysis. Health Psychol. 1996;15:398-402.

17- Rindal DB, Rush WA, Boyle RG. Clinical inertia in dentistry: a review of the phenomenon. J Contemp Dent Pract. 2008;9:1-9.

18- Roth SF, Heo G, Varnhagen C, Glover KE, Major PW. Job satisfaction among Canadian orthodontists. Am J Orthod Dentofacial Orthop. 2003; 123:695-700.

19- Sarita PT, Witter DJ, Kreulen CM, Matee MI, van't Hof MA, Creugers N. Decayed/missing/filled teeth and shortened dental arches in Tanzanian adults. Int J Prosthodont. 2004;17:224-30.

20- Sturmberg JP. Implementing best practice guidelines: the influence of personal characteristics. J Eval Clinical Pract. 1999;5:223-6.

21- Tanzania. Central Oral Health Unit. Annual regional dental services reports. Dar es Salaam: Central Oral Health Unit, Ministry of Health; 2005

22- Tanzania. Central Oral Health Unit. Policy guidelines for oral health services in Tanzania. Dar es Salaam: Central Oral Health Unit, Ministry of Health; 2002

23- Tanzania. Central Oral Health Unit. Proceedings of the Regional Dental Officers' meeting; 1994 Apr 5-7; Arusha. Dar es Salaam: Central Oral Health Unit, Ministry of Health; 1994.

24- Tanzania. Central Oral Health Unit. Proceedings of the Regional Dental Officers' meeting; 1996 Apr 22-24; Tanga. Dar es Salaam: Central Oral Health Unit, Ministry of Health; 1996.

25- Tanzania. Vision 2025. Donor-Dependence syndrome and defeatist development mindset [text on the internet]. Dar es Salaam; c2008. [cited 2008 Feb 12]. Available from: http://www.tanzania.go.tz/ vission 2025f.html 